\title{
(2) OPEN ACCESS \\ Evaluating the effectiveness of digital communication within the National Medication Safety Network for England
}

\author{
Samrina Bhatti, ${ }^{1,2}$ Nicola Wake, ${ }^{2}$ Yogini Jani ${ }^{1,3}$
}

\begin{abstract}
${ }^{1}$ Centre for Medicines Optimisation Research and Education, University College London Hospitals NHS Foundation Trust, London, UK ${ }^{2} \mathrm{NHS}$ Specialist Pharmacy Service, London North West Healthcare, Harrow, UK ${ }^{3}$ School of Pharmacy, University College London, London, UK
\end{abstract}

\section{Correspondence to}

Samrina Bhatti, Centre for Medicines Optimisation Research and Education, University College London Hospitals NHS Foundation Trust, London NW1 2BU, UK; samrina.bhatti1@nhs.net

Received 7 September 2020 Revised 22 November 2020 Accepted 1 December 2020

EAHP Statement 5: Patient Safety and Quality Assurance.

Check for updates

(C) European Association of Hospital Pharmacists 2021. Re-use permitted under CC BY-NC. No commercial re-use. Published by BMJ.

To cite: Bhatti S, Wake N, Jani Y. Eur J Hosp Pharm Epub ahead of print: [please include Day Month Year]. doi:10.1136/

ejhpharm-2020-002517

\section{ABSTRACT}

Objectives The medication safety officer (MSO) role was created following a patient safety alert, with an action for MSOs to be active participants in a national network in England, which included regular online webinar meetings and an online forum. The aim of the study was to assess the effectiveness of digital platforms in facilitating interaction and communication by the MSO network. The objectives were to establish the proportion of MSOs who interact through monthly webinars and the online forum. A secondary objective was to identify barriers and facilitators for engaging digitally within the MSO network.

Methods An online survey was used alongside semistructured interviews. The online survey was disseminated to all 400 MSOs registered with the UK Department of Health Central Alerting System from December 2018 to February 2019. Interviewees were identified purposively through snowball sampling and voluntarily through the survey.

Results 84 MSOs responded to the survey (21\% response rate) and 10 participated in the semistructured interviews. The majority of the respondents were pharmacists $(79 / 84,94 \%)$ from NHS large healthcare providers (44/84, 52\%). MSO respondents (61/84, 73\%) joined the monthly webinar and $47 / 84$ (56\%) believed the webinar was useful for networking. Ten (12\%) did not attend the webinars due to technical difficulties or lack of time. The online forum was used less frequently, with a third $(27 / 84,32 \%)$ that had never used it.

Conclusions Digital communications through webinars and online forums were perceived by respondents as a way to facilitate networking but require a robust information technology infrastructure that can be accessed without difficulty. User-friendly platforms can help the MSO network achieve critical mass and greater interaction, allowing timely access to information.

\section{INTRODUCTION}

In 2017, the WHO launched its third Global Patient Safety Challenge: Medication Without Harm. ${ }^{1}$ Recognising that unsafe medication practices and medication errors are a leading cause of injury and avoidable harm in healthcare systems across the world, Medication Without Harm aims to reduce severe avoidable medication related harms by $50 \%$, globally over 5 years. ${ }^{1}$

In England, the role of the medication safety officer (MSO) was created in March 2014 following a national patient safety alert ${ }^{2}$ that was jointly issued by the National Health Service England (NHSE) and the Medicines and Healthcare Products Agency
(MHRA). This alert called on organisations that provided healthcare, both in the National Health Service and in the independent sector, community pharmacy companies and organisations that commission healthcare to identify a named person to be that organisation's MSO. ${ }^{2}$ A key role for MSOs was to promote the safe use of medicines across their organisations and for them to be the main experts in this area. ${ }^{2}$

MSOs were expected to be active members of a newly created National Medication Safety Network, established by NHSE and the MHRA. ${ }^{2}$ An online information forum, hosted by the MHRA, and a regular webinar, hosted by NHSE, were set up to allow MSOs to discuss topics identified at local and national levels. ${ }^{3}$ In addition, the Specialist Pharmacy Service (SPS) ${ }^{4}$ supports MSOs and the National Medication Safety Network through the role of a specialist pharmacist lead for medication safety. This post supports individual MSOs and local and regional MSO groups and works with NHSE and the MHRA to provide content for and to support regular webinars and other events, including regional and national conferences. ${ }^{3}$

When the WHO challenge Medication Without $\mathrm{Harm}^{1}$ was launched, the role of the MSO and the National Medication Safety Network had been in place for 3 years, and there were 12 local, regional and sector-based MSO groups (in 2020, this number has grown to 18). The online information forum was in place and monthly webinars were planned and presented by SPS, NHSE and the MHRA. Previous surveys and informal feedback indicated that there was variability in the time MSOs were able to allocate to their role and MSOs reported barriers to sharing knowledge and information, including workplace isolation, time and availability, and geography. Virtual communities can be effective in overcoming these barriers by using digital platforms to enable interaction, including the use of webinars and online information forums. ${ }^{5}$ There is very little published about health professional networking through digital communications such as online groups and forums; however, these platforms have been shown to be beneficial for peerto-peer advice and support among academics and patients. $^{67}$

The aim of this formative evaluation was to understand how MSOs were networking, using digital platforms and to explore whether there were opportunities for enhancement. The objectives were to assess the perceived effectiveness of digital platforms in facilitating interaction and communication within the MSO network, to establish the 
proportion of MSOs who interacted through monthly webinars and online forums, and to identify barriers and facilitators for engaging digitally within the MSO network.

\section{METHODS}

A qualitative and quantitative mixed methods study was conducted using semistructured telephone interviews and an online survey.

The survey was developed by two researchers (YJ and SB) and included a mix of open and closed questions on the MSO role duration, time spent on MSO activities, access to and use of the online forum, opportunities for further networking, and any barriers and facilitators for each of these. Face validity was established through piloting within the author team. An online survey tool, Qualtrics, ${ }^{8}$ was used. The survey link was disseminated by email via the Central Alerting System (CAS) ${ }^{9}$ list that all MSOs are required to register with as a requirement of the national patient safety alert. The survey was open for responses from December 2018 to February 2019. The inclusion criteria were all participants who were in an MSO role during the time the survey was disseminated. MSOs working in an organisation outside of England were excluded. The email included an invitation to participate in telephone interviews to provide further insight. Survey responses were anonymous unless respondents volunteered their contact details for participation in the interviews. A reminder email was sent at 2 weeks after the original email; further reminders were given at the MSO annual conference and via the monthly MSO webinars. The MSO webinars were established as the primary way of participation in the national network and have an average of 120 attendees each month with the recording circulated to all MSOs by email and through the online forum. Survey responses were exported to Microsoft Excel. In case of any missing values for individual questions, the denominator was adjusted. Descriptive statistics were calculated for proportions; thematic analysis of free-text responses was carried out.

Semistructured telephone interviews were carried out using open-ended questions to explore the respondents' opinions on the MSO network and to explore ideas for improving the network activity using digital platforms. The participant consent was received through completion of the MSO survey. Information about the study was reiterated and consent was confirmed prior to the telephone interviews, providing the respondents an opportunity to ask questions or to withdraw from the study. Interviews were transcribed verbatim and were shared with the interviewees for validation. Transcripts were coded by one researcher (SB) and reviewed by a second researcher (YJ). Data were analysed using inductive thematic analysis.

Credibility of findings was assured through data triangulation using interview themes and survey responses.

Using the Health Research Authority decision toolkit ${ }^{10}$ study was considered a service evaluation and did not require ethical approval. However, good research practices were followed to ensure the participants' anonymity was maintained.

\section{RESULTS}

Eighty-four of 400 MSOs that were invited completed the online survey, which gave a response rate of $21 \%$. The majority of the survey respondents were pharmacists $(79 / 84,94 \%)$, with a small number of pharmacy technicians $(3 / 84,4 \%)$ and nurses $(2 / 84,2 \%)$. Over half the survey respondents were from large healthcare providers within the NHS (44/84, 52\%), four from independent sector large healthcare providers, four from clinical

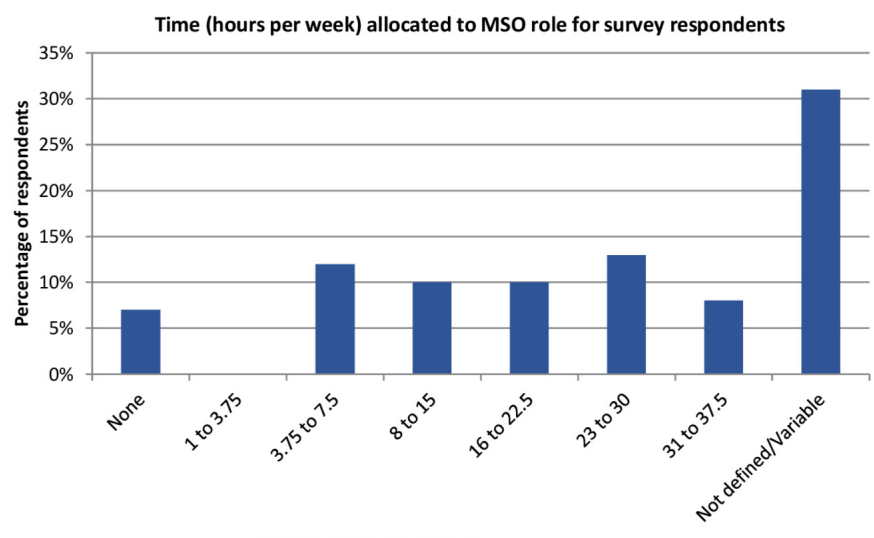

Number of hours per week

Figure 1 Distribution of the number of hours/week allocated to the MSO role in 2019. MSO, medication safety officer.

commissioning groups, two from NHS England, one from an 'other' independent sector and one from community pharmacy (multiples). The remaining 28 respondents did not state their sector. The allocated time for the MSO role varied among respondents, with a third (26/84) stating they had an undefined or a variable amount of time allocated to their MSO role (figure 1). Ten of the survey respondents agreed to participate in the semistructured interviews. Seven of the interviewees were from large healthcare providers; two were from community pharmacy (multiples); and one was from the independent sector.

\section{Webinars}

Most of the respondents $(61 / 84,73 \%)$ joined the webinars and considered the monthly frequency appropriate (table 1$)$. Twothirds $(55 / 84)$ believed the webinar content was 'just right' to enable learning about new or emergent risks, and half (44/84) responded the webinar content was just right for knowledge about medication safety and risk theory (figure 2). Approximately half $(47 / 84,56 \%)$ of the respondents believed the webinar was useful for networking via the chat function.

The interview respondents highlighted that with the monthly frequency, the chat function was considered more suitable for non-urgent medication safety issues. For timely advice on medication safety issues of an urgent nature, respondents stated that they were more likely to use email or telephone to contact MSOs.

Ten (12\%) survey respondents could not join the webinars, either due to technical difficulties or because of limited time within their MSO role. Individuals from the private and primary care sectors reported the web events were frequently tailored to those in secondary care and consequently did not attend.

Table 1 Survey respondents' opinions on the frequency of the MSO webinars

\begin{tabular}{ll}
\hline & $\mathbf{n}(\%)$ \\
\hline $\begin{array}{ll}\text { Do you 'attend' or join the monthly MSO webinar? } \\
\text { Yes }\end{array}$ & $61(73)$ \\
\hline No & $10(12)$ \\
\hline Response not given & $13(15)$ \\
$\begin{array}{l}\text { Do you think it would be beneficial to run the monthly MSO webinars more } \\
\text { frequently? }\end{array}$ \\
\hline Yes & $8(10)$ \\
\hline No & $62(74)$ \\
\hline Response not given & $14(17)$ \\
\hline MSO, medication safety officer. & \\
\hline
\end{tabular}

Bhatti S, et al. Eur J Hosp Pharm 2021;0:1-5. doi:10.1136/ejhpharm-2020-002517 


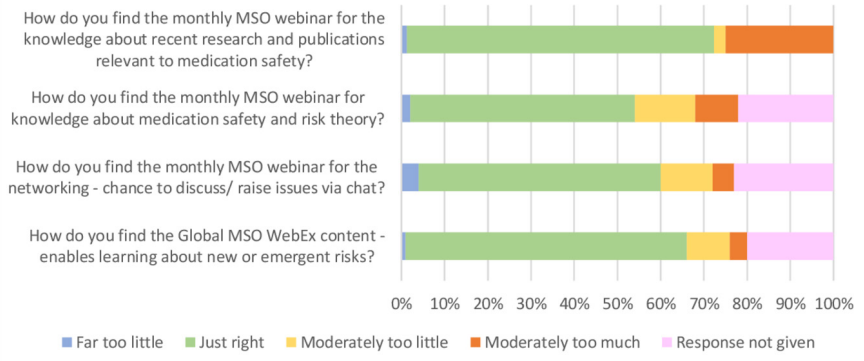

Figure 2 Survey respondents' opinions on the MSO webinars outlining content and knowledge acquired. MSO, medication safety officer.

\section{Online forum}

The online forum was used less frequently than the webinars, with approximately a third of the respondents $(27 / 84,32 \%)$ stating they had never used the forum and only $15 / 84(18 \%)$ used it more than once a month (table 2). Reasons for infrequent use included difficulty in gaining access due to security restrictions. Those that were able to access the forum felt it was not user friendly in terms of navigation, and it was non-responsive to topics raised as there were not enough MSOs using the platform. This was reiterated by interviewees who stated that learning was shared on the national, password-protected 'Future NHS' web platform, but this was most useful if the individual knew where information was located.

A small proportion of MSOs (9/84, 11\%) reported using the United Kingdom Clinical Pharmacy Association Medicines Safety and Quality subgroup forum to interact with other MSOs. The interview data showed that this forum was considered more user friendly and had greater responsiveness. Respondents indicated that the functionality of receiving an email notification for new posts relating to a particular forum was beneficial. However, access to the forum is limited to subscribers who purchase membership. Others (4/84, 5\%) developed their own email forums regionally with individuals who were known to them through regional meetings.

Overall, interviewees identified a need for a more cohesive network structure both locally and regionally. In some cases,

\begin{tabular}{|l|l|}
\hline Table 2 Survey respondents' use of the MSO online forum \\
\hline & $\mathrm{n}(\%)$ \\
\hline How often do you use the MSO online forum? & $\mathrm{n}=84$ \\
\hline Never & $27(32)$ \\
\hline Once a week & $12(14)$ \\
\hline Once every 3 weeks & $1(1)$ \\
\hline Once a month & $2(2)$ \\
\hline Once every couple of months & $10(12)$ \\
\hline Once every 6 months & $15(18)$ \\
\hline Unsure & $6(7)$ \\
\hline Response not given & $11(13)$ \\
\hline Are there any other online group forums you use to interact with other MSOs? & \\
\hline Yes & $17(20)$ \\
\hline No & $55(65)$ \\
\hline Response not given & $12(14)$ \\
\hline What online group forums do you use to interact with other MSOs? & $\mathrm{n}=17$ \\
\hline Kahootz & $1(6)$ \\
\hline Local group & $1(6)$ \\
\hline Medicines Safety Nurse Forum & $1(6)$ \\
\hline Regional group & $4(24)$ \\
\hline Twitter & $1(6)$ \\
\hline UK Clinical Pharmacists' Association & $9(53)$ \\
\hline MSO, medication safety officer. & \\
\hline
\end{tabular}

MSOs reported that, despite a desire to connect and network with other MSOs across different sectors, the lack of access to MSO colleagues' contact details prevented this.

\section{DISCUSSION}

Overall, the monthly webinars were the primary mechanism for MSOs to network and communicate, with a lower rate of engagement through the online forums. Local, regional and other online forums or direct contact where possible were favoured as alternatives to facilitate networking across diverse organisations and large geographical spread. Due to low responses across various sectors, we were unable to determine if there were sector-related variations in the uptake of digital communications provided by the network.

While there is evidence that clinical or healthcare professional networks improve the quality and safety of patient care, the effectiveness and sustainability of these networks depend on a number of factors, including effective communication strategies, a critical mass or sense of community and collaborative trusting relationships, common purpose, and adequate resources and cooperative structures. ${ }^{11-13}$ This was reflected in our results, which showed that, although webinars and forums were considered useful communication aids, barriers such as access through technology and timing remain. The findings are consistent with others who have reported positive outcomes when using webinars for communication in terms of the quality, value and relevance, but acknowledged limitations and concerns surrounding timing, topics and costs. ${ }^{14}$ The webinar content may influence engagement of MSOs from various sectors, and this was reflected in the responses, which indicated that depending on the learning being shared then they would attract a greater audience from the relevant sector. Therefore, for wider participation and engagement, a greater variety of cross-sectoral topics should be considered. These limitations of time and content have been managed by the SPS medication safety lead, who coordinates the webinar programme in collaboration with the national team.

Originally designed as a closed access forum to provide a 'safe' environment for MSOs, our results suggest that the MSO online forum has been less effective for promoting and fostering networking partly due to the restricted access. Use of forums as educational tools and their social influence and behaviour have been shown to encourage reflection and dialogue about challenging communication situations, ${ }^{15}{ }^{16}$ but the online design is recognised as an important aspect to enable a virtual discussion. ${ }^{16}$ Accessibility to and navigation through the online MSO forum were recognised and reported barriers, suggesting there may be a need to improve these. This is particularly important with the development of the new Patient Safety Specialists network, ${ }^{17}$ which will have overlap in terms of the scope and areas of interest, but users would not necessarily have access to the MSO webinar forum and webinar. The effectiveness of networks is reliant on collective intelligence from high usage. ${ }^{11}$ Thus, digitally supported active forums have an important role in sharing ideas, challenges and resources, such as newsletters and bulletins to maximise the collaboration within and between the different safety networks, irrespective of organisational or geographical boundaries.

Our findings indicate that MSOs would prefer a centralised user-friendly online platform of resources and examples of practice for implementing patient safety alerts and national guidance. While examples such as the WHO Good Practice Repository ${ }^{18}$ and the Future NHS platform exist, these neither provide an opportunity for chat function nor does it allow MSOs to upload 
and share documents from meetings and webinars. Our findings suggest that in the absence of a central digital platform, MSOs from different sectors may have taken varied approaches to shared learning. For example, the community MSOs share learning via websites or bespoke online sharing platforms through other organisations' technology infrastructure ${ }^{19}$ and other sectors communicated via mailing lists. Understanding the use of alternative digital communications can inform future digital development for the network.

The main limitation of this work is the low response rate that may not be fully representative of the entire network. MSOs are required to register to the CAS email alert system when in post and this was therefore considered the most up-to-date list of MSOs. Any delays in updating the CAS email list or issues of local access through generic email addresses may have contributed to the low response rate. However, this was addressed by publicising and reminding the MSOs about the survey through the monthly MSO webinars and the annual MSO conference. Furthermore, there may be a respondent bias in that those who engaged with the MSO network were also more likely to participate in the survey. However, the study does provide useful insights to barriers and facilitators for effective networking, especially with the ongoing focus and strategy for reducing medication related harm in the NHS. ${ }^{20}$ Additionally, we do not know of any changes to practice that the MSOs may have made based on their involvement via these digital communications. Further work is required to assess to assess the MSO network effectiveness. Findings from Brown et $a l^{12}$ indicate that networks that had a positive impact on quality of care and patients' outcomes were those that had adequate resources, credible leadership and efficient management coupled with effective communication strategies and collaborative trusting relationships. Although the study focused on the English MSO network, it is one of the few national networks for medication safety, and the learning could have relevance for others intending to take a similar approach internationally or in a different sector within England. The learning was also formative for the continued development of the network.

In conclusion, digital communications through webinars and online forums can facilitate networking but require a robust information technology infrastructure that can be accessed without difficulty.

Shared learning and mutual support are of great importance in a well-functioning network. $\square$ Interaction through digital means can help create more opportunities to build meaningful relationships with others when geographical distance and time

What this paper adds

What is already known on this subject

- Clinical networks are promoted as a strategy to improve patient care.

- Core features for effective networks include collective intelligence, cooperative structures and effective communication strategies.

What this study adds

- Members of the medication safety officer (MSO) network in England perceived digital communications to facilitate networking.

- Ease of access and user-friendly platforms were reported as enabling greater networking across and between MSOs from different healthcare sectors. allocation to role are varied and limited. By leveraging the power of the network through digital technology, individuals can interact on a more flexible basis.

\section{Twitter Samrina Bhatti @SamrinaUK}

Contributors SB: study conception, design, analysis and interpretation, drafting of the first manuscript; NW: study conception, data analysis and interpretation, review and finalisation of the manuscript. YJ: study conception, design, analysis and interpretation, review and finalisation of the manuscript.

Funding The authors have not declared a specific grant for this research from any funding agency in the public, commercial or not-for-profit sectors.

\section{Competing interests None declared.}

\section{Patient consent for publication Not required.}

Ethics approval Using the Health Research Authority decision toolkit, we report that this study was considered a service evaluation and did not require ethical approval. However, good research practices were followed to ensure the participants' anonymity was maintained.

Provenance and peer review Not commissioned; externally peer reviewed.

Data availability statement All data relevant to the study are included in the article or uploaded as supplementary information.

Open access This is an open access article distributed in accordance with the Creative Commons Attribution Non Commercial (CC BY-NC 4.0) license, which permits others to distribute, remix, adapt, build upon this work non-commercially, and license their derivative works on different terms, provided the original work is properly cited, an indication of whether changes were made, and the use is noncommercial. See: http://creativecommons.org/licenses/by-nc/4.0/.

\section{REFERENCES}

1 The World Health Organisation. The third WHO Global Patient Safety Challenge: Medication Without Harm [online]. Available from: The World Health Organisation. The third WHO Global Patient Safety Challenge: Medication Without Harm 2017.

2 MHRA and NHS England. Patient safety alert: stage three: directive improving medication error incident reporting and learning, 2014. Available: https://www. england.nhs.uk/2014/03/med-devices/ [Accessed 20 Mar 2014].

3 Specialist Pharmacy Service. Medication Safety Officer Handbook [online], 2018. Available: https://www.sps.nhs.uk/articles/medication-safety-officer-handbook/ [Accessed 28 Jun 2018].

4 Specialist Pharmacy Service. Specialist Pharmacy Service [online], 2020. Available: https://www.sps.nhs.uk [Accessed Jan 2020]

5 Walsh K. Virtual communities of practice: overcoming barriers of time and technology. J Med Internet Res 2014;16:e185.

6 Cree-Green M, Carreau A-M, Davis SM, et al. Peer mentoring for professional and personal growth in academic medicine. J Investig Med 2020;68:jim-2020-001391.

7 Lobban F, Akers N, Appelbe D, et al. A web-based, peer-supported self-management intervention to reduce distress in relatives of people with psychosis or bipolar disorder: the react RCT. Health Technol Assess 2020;24:1-142.

8 Qualtrics. Qualtrics [online]. Available: https://www.googleadservices.com/ pagead/aclk?sa=L\&ai=DChcSEwip46yM_pzoAhUFtOOKHVLOByEYABAAGgJkZw\& ohost=www.google.com\&cid=CAESQOD2iJbFI3ruiG1W7WXSNfMp077I6QeH_ 6KS6Xdue2nnnOUGVHm_93LGmB_a8exlsY6DrgyFWOAUEpkJ4mVwkU4\& sig=A0D64_2AnrV684G-w07Ua9rolXAaHI3h4g\&q=\&ved=2ahUKEwiS66SM_ pzoAhWkmFwKHf-ZDNEQ0Qx6BAgfEAE\&adurl=.2020 [Accessed Jan 2020].

9 MHRA. Central Alerting System [online], 2020https://www.cas.mhra.gov.uk/Home. aspx [Accessed Jan 2020].

10 NHS Health Research Authority, 2020. Available: http://www.hra-decisiontools.org.uk/ ethics/ [Accessed Mar 2020].

11 The Health Foundation. Effective networks for improvement; Developing and managing effective networks to support quality improvement in healthcare [online] Available from: The Health Foundation. Effective networks for improvement; Developing and managing effective networks to support quality improvement in healthcare 2014

12 Brown BB, Patel C, Mclnnes E, et al. The effectiveness of clinical networks in improving quality of care and patient outcomes: a systematic review of quantitative and qualitative studies. BMC Health Serv Res 2016;16:360.

13 Cunningham FC, Ranmuthugala G, Plumb J, et al. Health professional networks as a vector for improving healthcare quality and safety: a systematic review. BMJ Qual Saf 2012;21:239-49.

14 Buxton EC, Burns EC, De Muth JE. Professional development webinars for pharmacists. Am J Pharm Educ 2012;76:155

15 Chomutare T, Arsand E, Fernandez-Luque L, et al. Inferring community structure in healthcare forums. An empirical study. Methods Inf Med 2013;52:160-7. 
16 Makoul G, Zick AB, Aakhus M, et al. Using an online forum to encourage reflection about difficult conversations in medicine. Patient Educ Couns 2010;79:83-6.

17 NHS Improvement. Introducing patient safety specialists [online], 2019. Available: https://improvement.nhs.uk/resources/introducing-patient-safety-specialists/ [Accessed 2 Jul 2017].

18 Specialist Pharmacy Service. Using the WHO Good Practice Repository [online], 2018. Available: https://www.sps.nhs.uk/articles/using-the-who-good-practice-repository/ [Accessed 5 Nov 2018].
19 NPA medication safety update (MSO report) quarter 1 (England), 2020. Available: https://www.npa.co.uk/news-and-events/news-item/npa-medication-safety-updatemso-report-quarter-1-2020-england/ [Accessed Oct 2020].

20 NHS Improvement. National medicines safety programme [online], 2020. Available: https://improvement.nhs.uk/resources/national-medicines-safety-programme/ [Accessed 8 Feb 2019]. 